\title{
Estabelecimento e multiplicação in vitro de brotos no processo de micropropagação de cultivares de bananeira (Musa spp.)
}

\author{
Hérica Santos de OLIVEIRA ${ }^{1}$, Oriel Filgueira de LEMOS², Vicente Savonitti MIRANDA³, Hellen Cristina da \\ Paixão MOURA ${ }^{4}$, Meiciane Ferreira CAMPELO ${ }^{5}$, Lana Roberta Reis dos SANTOS ${ }^{6}$
}

\begin{abstract}
RESUMO
A banana (Musa spp.) é uma das frutas mais consumidas no mundo, e amplamente cultivada no Brasil, porém doenças como as sigatokas, negra e amarela, vêm reduzindo a sua produção. A disponibilização imediata de novas cultivares resistentes às principais doenças é limitada pela propagação convencional. A micropropagação é uma alternativa para a produção de mudas com qualidade fitossanitária e vegetativa, mas apresenta fatores que dificultam sua aplicação como a contaminação por fungos e bactérias, associada à oxidação dos explantes. O objetivo desse trabalho foi adaptar e/ou otimizar as etapas do processo de micropropagação para diferentes cultivares de bananeira, por meio do controle de oxidação, contaminação, e multiplicação de brotos, sendo utilizadas as cultivares Caipira (AAA), BRS Caprichosa (AAAB), Pacovan Ken (AAAB), Preciosa (AAAB), PV 03-76 (AAAB), Thap Maeo (AAB). No estudo foram utilizados o antibiótico sulfato de estreptomicina e o fungicida Opera ${ }^{\circledR}$ (BASF) visando reduzir a contaminação in vitro provocada por bactérias e fungos, além do anti-oxidante PVP (polivinilpirrolidona) para controlar a oxidação. Houve redução da contaminação com uso do sulfato de estreptomicina à concentraçáo de $100 \mathrm{mg}$ $\mathrm{L}^{-1}$ e da oxidaçáo com PVP a $4 \mathrm{~g} \mathrm{~L}^{-1}$. Na fase de multiplicaçấo de brotos, as cultivares apresentaram médias que variaram de 1,90 a 4,75 brotos/explante. A cultivar caipira (AAA) destacou-se das demais com a maior taxa de multiplicação de brotos após três subcultivos, média de 41,50 brotos por rizoma.
\end{abstract}

PALAVRAS-CHAVE: banana, oxidação, contaminação, multiplicação in vitro.

\section{Establishment and in vitro multiplication of banana (Musa spp.) cultivars with the use of PVP (Polyvinylpyrrolidone)}

\begin{abstract}
The banana (Musa spp) is one of the most consumed fruits in the world and is widely consumed in Brazil, but diseases such as yellow and black sigatoka have been reducing its production. The immediate availability of new cultivars resistant to major diseases is limited by conventional propagation. The micropropagation, is an alternative for the production of seedlings with phytosanitarium and vegetative quality, but presents factors that difficult its application such as contamination by fungi and bacteria, associated with oxidation of the explants. The objective of this work was to adapt and/or optimize the stages of the micropropagation of banana cultivars, through the control of oxidation, contamination, and multiplication of shoots. The cultivars used Caipira (AAA), BRS Caprichosa (AAAB), Pacovan Ken (AAAB), Preciosa (AAAB), PV 03-76 (AAAB), Thap Maeo (AAB) were subjected to different micropropagation stages. In the study we used the streptomycin sulfate antibiotic and fungicide Opera ${ }^{\oplus}$ (BASF) to reduce contamination in vitro caused by bacteria and fungi, besides the anti-oxidant PVP (polivinilpirrolidona) to control the oxidation. We found contamination reduction with the use of streptomycin sulfate in the concentration of $100 \mathrm{mg} \mathrm{L}^{-1}$ and of oxidation with PVP at $4 \mathrm{~g} \mathrm{~L}^{-1}$. At the stage of multiplication of shoots, the cultivates showed means ranging from 1,90 to 4,75 shoots / explant. The cultivate Caipira (AAA) stood out from the others with the highest rate of shoot multiplication after three subcultivations, 41,50 shoots per rhizome average.
\end{abstract}

KEYWORDS: Banana, oxidation, contamination, in vitro multiplication.

\footnotetext{
1 Embrapa Amazônia Oriental. hericaeng@yahoo.com.br

2 Embrapa Amazônia Oriental. orie@@cpatu.embrapa.br

3 UFRA. vicente.miranda@ufra.edu.br

4 UFRA. hcris20@yahoo.com.br

${ }^{5}$ Embrapa Amazônia Oriental. agro.meici@yahoo.com.br

${ }^{6}$ Embrapa Amazônia Oriental. lana.robert@hotmail.com
} 


\section{INTRODUÇÃO}

A bananeira está entre as culturas de maior importância econômica para os países tropicais e subtropicais. Da família das Musaceas é cultivada em todos os estados brasileiros, desde a faixa litorânea até os planaltos do interior (Borges $e t$ al. 2006). O Brasil é o segundo maior produtor mundial de banana, com uma produção de 6.998,150 toneladas em 2008, em uma área plantada de aproximadamente 522,867 hectares (Produção Agrícola Municipal, IBGE 2008). A renovação dos plantios e a ampliação da área cultivada são dependentes da disponibilidade de grandes quantidades de mudas com elevada qualidade fitossanitária que tem influência na fitossanidade e produtividade do bananal.

O maior problema do cultivo da bananeira no Brasil é a falta de cultivares comerciais produtivas e que apresentam resistência às principais pragas e doenças (Silva et al. 2006). O Estado do Pará destacou-se, de 1998 a 2000, como o maior produtor de bananas do país. Em 2005, tornou-se o terceiro colocado, com praticamente a mesma produçáo do Estado da Bahia, o segundo produtor nacional. A ocorrência de doenças tem contribuído para a reduçáo da produtividade, destacandose a sigatoka-negra, sigatoka-amarela, mal-do-Panamá e moko (Poltronieri et al. 2009).

Existem quatro padrôes ou tipos principais de variedades de bananeira: Prata, Maçã, Cavendish (banana D'Água) e Terra. Dentre cada tipo, há uma ou mais variedades. No Estado do Pará tem sido avaliado o comportamento nas condições edafoclimáticas do município de Belém, PA, de novas variedades resistentes às sigatokas amarela e negra (Prata Caprichosa, Caipira, Thap Maeo, PV-0376, Pacovan Ken), que apresentaram produção de cacho com peso médio que variaram entre 10 a $20 \mathrm{Kg}$, com boa aceitabilidade no mercado e que precisam ser multiplicadas para serem adotadas no sistema de produção (Nascimento et al. 2009).

O sistema de propagaçáo convencional da bananeira é lento e possui baixo rendimento, mas estudos recentes têm mostrado que a adoção da micropropagação é uma alternativa viável para a produçáo comercial de mudas, aumentando de maneira considerável o número de plantas livres de pragas e doenças, dentro de um curto espaço de tempo (Sá e Braga 2002). Plantas de bananeira micropropagadas sobrevivem mais no campo, e crescem mais rapidamente nos primeiros estádios de desenvolvimento do que as mudas convencionais. Além disso, plantas micropropagadas apresentam maior precocidade florescendo até quatro meses antes que as plantas propagadas de forma convencional, apresentam também uniformidade de produção, desta maneira proporcionam colheitas superiores (Álvares e Caldas 2002).

No processo de micropropagação da bananeira a fase mais crítica é o estabelecimento dos ápices caulinares in vitro, em função da contaminação por fungos e bactérias e pela oxidação caracterizada pelo escurecimento do ápice caulinar ou até mesmo do meio de cultivo (Grattapaglia e Machado 1998). A oxidação é causada pela reação das polifenoloxidases sobre compostos fenólicos e, no caso da bananeira, pode levar os ápices caulinares à morte, nas fases iniciais de desenvolvimento ou prejudicar o desempenho da fase de multiplicaçáo (Souza et al. 2000; Vuylsteke e Langhe 1985).

A adição de antioxidantes como o ácido cítrico, ácido ascórbico, peróxido de hidrogênio, polyvinilpirrolidone (PVP) e carvão ativado ao meio de cultura após a autoclavagem, é relatada na literatura tanto para bananeira como para outras culturas, como alternativa para a diminuição do processo de oxidação. Para a diminuição da oxidação, Grattapaglia e Machado (1998) recomendam a adição de antioxidantes ao meio de cultivo ou o pré-tratamento dos explantes em solução contendo antioxidantes.

O PVP (polivinilpirrolidona) é um antioxidante que tem sido bastante empregado, sendo que os fenóis são adsorvidos pelo PVP por meio de ligaçóes de hidrogênio, o que previne a oxidação e polimerização, além de adsorver os produtos da oxidação fenólica, ou seja, as quinonas (Pasqual et al. 1997). Segundo Augusto e Biasi (2002), a adição de $1 \mathrm{~g} \mathrm{~L}^{-1}$ de PVP solúvel no meio sólido controla a oxidação de amoreira-preta (Rubus sp.) e, de acordo com Cordeiro et al. (2002), foi altamente eficiente no controle da oxidaçâo em sementes de paricá. Figueiredo et al. (2001) utilizaram na micropropagação de biribá (Rollinia mucosa Jacq Baill) PVP a $0,5 \mathrm{~g} \mathrm{~L}^{-1} \mathrm{e}$ foi eficiente no controle da oxidação. No estabelecimento de embrióes de guarirobeira (Syagrus oleracea (MART.) BECC.) o PVP a $0,4 \mathrm{~g} \mathrm{~L}^{-1}$ não foi eficiente (Melo et al. 2001), mas náo foram encontrados relatos do uso dessa substância para controle de oxidaçáo em bananeira.

Segundo Grattapaglia e Machado (1990), a eficiência de um protocolo de micropropagaçáo pode ser avaliada, principalmente, pela taxa média de multiplicação ao longo dos subcultivos, pelo número final de mudas obtidas e pela porcentagem de plantas que conservem as características genéticas iniciais. Uma série de trabalhos tem sido desenvolvida visando estabelecer protocolos seguros para a multiplicação in vitro de cultivares de bananeira (Cronauer e Krikorian 1984; Hwang et al. 1984; Banerjee e De Langhe 1985; Wong 1986; Angarita e Perea 1991; Sandoval et al. 1991). Esses trabalhos demonstraram que para cada genótipo devem ser realizadas modificaçôes nos protocolos de micropropagação quanto ao tipo de explante, concentraçáo de componentes do meio de cultura e as condiçóes físicas do ambiente.

O presente trabalho teve como objetivo instituir as condiçôes de estabelecimento e multiplicação in vitro no processo de micropropagaçáo para diferentes cultivares de bananeira resistentes às doenças (sigatoka-negra, sigatoka- 
amarela, mal-do-Panamá e moko), visando a rápida multiplicação de plantas com qualidade fitossanitária e vegetativa.

\section{MATERIAL E MÉTODOS}

Rizomas de bananeira das cultivares Caipira, BRS Caprichosa, Pacovan Ken, Preciosa, PV 03-76 e Thap Maeo, resistentes as principais doenças que atacam a cultura (sigatokanegra, sigatoka-amarela, mal-do-Panamá e moko), foram retirados de matrizes da Unidade de Observação instalada no campo experimental na Embrapa Amazônia Oriental, em Belém-PA, no mês de junho de 2009 (época chuvosa), e enviados para o Laboratório de Biotecnologia e Recursos Genéticos. Foi feita uma pré-limpeza dos rizomas com lavagem em água corrente e imersão na solução de fungicida Opera ${ }^{\circledast}$ (BASF) a $2 \mathrm{~mL} \mathrm{~L}^{-1}$ por 20 minutos. Após a pré-limpeza, os rizomas foram colocados em estufa a $38^{\circ} \mathrm{C}$ por uma semana. Em seguida, os rizomas foram reduzidos para cerca de 6 a $8 \mathrm{~cm}$ e tratados duplamente com fungicida $2 \mathrm{~mL} \mathrm{~L}^{-1}$ por 20 minutos, $1 \mathrm{~mL} \mathrm{~L}^{-1}$ por mais 7 minutos.

A assepsia dos rizomas previamente preparados, foi realizada em câmara de fluxo laminar asséptica, primeiramente com álcool etílico $70 \%$ por 1 minuto, seguido de imersão em hipoclorito de sódio ( $\mathrm{NaClO}$ ) a 2,5\% e 2 gotas de Tween 20, durante 15 minutos. Posteriormente, foram submetidos a cinco lavagens em água destilada autoclavada. Em seguida, foram retiradas as bainhas de folhas até a obtenção de ápices caulinares com cerca de 1,5 a 2,0 cm, estes explantes foram mergulhados em solução de ácido cítrico na concentração de $50 \mathrm{mM}$ antes de serem inoculados em meio de cultivo.

Para evitar a contaminação por bactérias e a oxidação dos explantes, adicionou-se aos meios de cultura de estabelecimento e de indução de brotos, antes da autoclavagem, $100 \mathrm{mg} \mathrm{L}^{-1}$ de sulfato de estreptomicina e $0,4 \%$ de PVP, respectivamente.

Os explantes foram inoculados em tubos de ensaio contendo $20 \mathrm{~mL}$ de meio MS (Murashige Skoog 1962), suplementado com $30 \mathrm{~g} \mathrm{~L}^{-1}$ de sacarose, vitamina MS, 2,5 $\mathrm{mg} \mathrm{L}^{-1}$ de BAP (6-benzilamino purina), PVP (polivinilpirrolidona) a $4 \mathrm{~g} \mathrm{~L}^{-1}, 100$ $\mathrm{mg} \mathrm{L}^{-1}$ de Sulfato de Estreptomicina solidificado com Phytagel a $2 \mathrm{~g} \mathrm{~L}^{-1}$. Os tubos foram tampados com papel alumínio e vedados com filme de PVC sendo mantidos por uma semana em sala de crescimento sob fotoperíodo de $16 \mathrm{~h}$, com intensidade de luz de $25 \mu \mathrm{mol} . \mathrm{s}^{-1} . \mathrm{cm}^{-2}$ e temperatura de $25 \pm 3{ }^{\circ} \mathrm{C}$. Após esse período, foram eliminados os tecidos escurecidos visando controlar a oxidação, em virtude da liberação de polifenóis que interferem no desenvolvimento. Os explantes que apresentavam sintomas aparentes de contaminação foram submetidos à solução de sulfato de estreptomicina a $100 \mathrm{mg} \mathrm{L}^{-1}$ por 3 minutos, antes de serem transferidos para frascos de vidro com $40 \mathrm{~mL}$ de meio de indução de brotos (MS +30 $\mathrm{g} \mathrm{L}^{-1}$ de sacarose + vitamina MS + BAP a $4,5 \mathrm{mg} \mathrm{L}^{-1},+$ PVP a $4 \mathrm{~g} \mathrm{~L}^{-1}$, solidificado com Phytagel a $2 \mathrm{~g} \mathrm{~L}^{-1}+$ Sulfato de Estreptomicina a $100 \mathrm{mg} \mathrm{L}^{-1}$ ), tampados com tampas plásticas e vedados com filme de PVC. Após cinco semanas de cultivo, nas mesmas condiçôes supracitadas, em meio de indução de brotos, os ápices caulinares sofreram corte central, ou seja, foram seccionados longitudinalmente em duas partes, para quebrar a dominância apical, e foram introduzidos em meio de cultivo de corte longitudinal do explante (MS + 30 $\mathrm{g} \mathrm{L}^{-1}$ de sacarose + vitamina MS + BAP a 4,5 mg. $\mathrm{L}^{-1}+$ PVP a $4 \mathrm{~g}$ $\mathrm{L}^{-1}$, solidificado com Phytagel a $2 \mathrm{~g} \mathrm{~L}^{-1}$ ), todo este procedimento foi realizado em condiçóes assépticas, em câmara de fluxo laminar (Figura 1). Ressalte-se que a fase de estabelecimento até a indução de brotos ocorreu em 10 semanas.

$\mathrm{O}$ valor do $\mathrm{pH}$ de todos os meios de cultura foi ajustado para 6,1 antes da autoclavagem por 20 minutos, a $120{ }^{\circ} \mathrm{C} \mathrm{e}$ sob pressáo de 1,5 atm. Os tratamentos foram constituídos com diferentes números de repetiçóes variando de nove a 35 , e o delineamento estatístico foi o inteiramente casualizado. A avaliação do experimento foi realizada quanto à percentagem de perda de explantes por cultivar.

Após a realização dos cortes longitudinais e do cultivo dos explantes por 6 semanas, ocorreu a induçáo de brotaçóes, sendo estas individualizadas, após limpeza do material (retirando tecidos externos oxidados e parte aérea) e transferidas para frascos com $40 \mathrm{~mL}$ de meio de multiplicação de brotos, contendo MS + 30
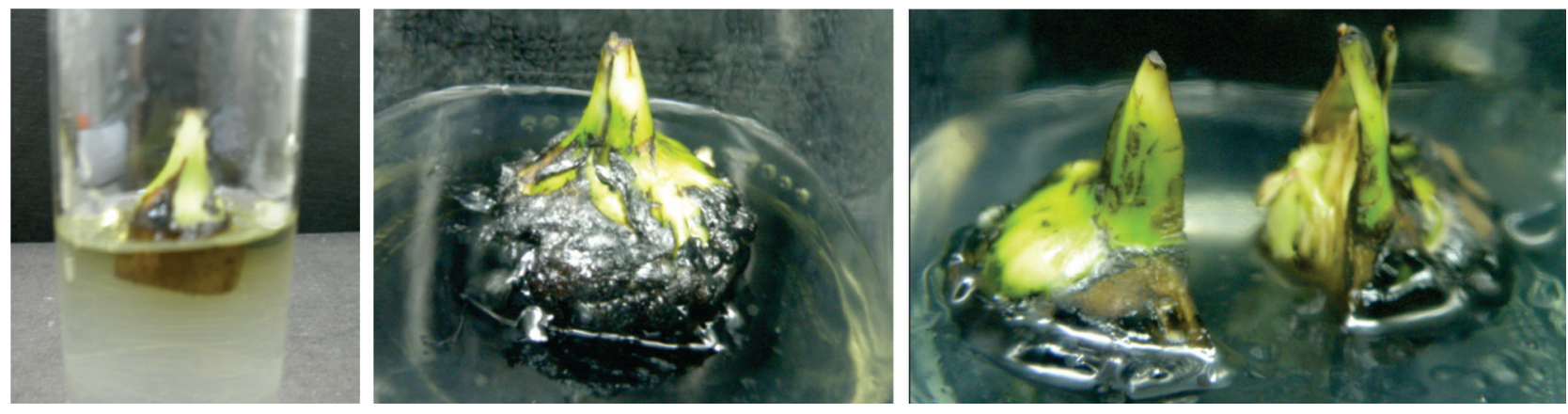

Figura 1 - Fases do cultivo dos meristemas: A. Em meio de estabelecimento; B. Em Meio de indução de brotos; C. Corte central longitudinal do ápice caulinar. 
$\mathrm{g} \mathrm{L}^{-1}$ de sacarose + vitamina $\mathrm{MS}+\mathrm{BAP}$ a $4,5 \mathrm{mg} \mathrm{L}^{-1}+\mathrm{PVP}$ a $4 \mathrm{~g}$ $\mathrm{L}^{-1}$ e solidificado com Phytagel a $2 \mathrm{~g} \mathrm{~L}^{-1}$, tampados com tampa plástica e vedados com filme de PVC. $\mathrm{O}$ pH foi ajustado para 6,1 previamente à autoclavagem a $121{ }^{\circ} \mathrm{C}$ e sob pressão de 1,5 atm por 20 minutos. $\mathrm{O}$ experimento foi subcultivado por três vezes a cada quatro semanas para multiplicação dos brotos.

Foram inoculados até cinco explantes por frasco, constituído de quatro repetiçóes para cada cultivar. O delineamento estatístico foi o inteiramente casualizado.

A avaliação feita a cada subcultivo foi quanto ao número de brotos por rizoma após o $1^{\circ}, 2^{\circ}$ e $3^{\circ}$ subcultivos e número de brotos por explante após o $2^{\circ}$ e $3^{\circ}$ subcultivos, para cada cultivar. Os dados foram submetidos à análise de variância, utilizando o programa estatístico SISVAR (Ferreira 2009), e as médias foram comparadas pelo teste de Tukey a $5 \%$ de probabilidade, com realização de testes de homogeneidade de variância e testes de homocedasticidade de Hartley e Cochran, com transformação logarítmica dos dados.

\section{RESULTADOS E DISCUSSÃO}

No estabelecimento dos explantes (Figura 2), foi observada contaminação por bactérias nos primeiros dias, seguida de perda por oxidação. A perda por contaminação e/ou oxidaçáo alcançou $66,67 \%, 51,85 \%, 50,00 \%, 37,50 \%$ e $9,09 \%$, nas cultivares Pacovan Ken, PV 03-76, BRS Caprichosa, Thap Maeo e Caipira, somente a cultivar Preciosa se desenvolveu bem nesta fase não apresentando perdas. Entretanto, após transferência para meio de indução de brotos, todas as cultivares continuaram manifestando perda por contaminação e/ou oxidação, sendo 100,00\% para a cultivar Pacovan Ken, $50,00 \%$ para a Caipira, $40,00 \%$ para as cultivares BRS Caprichosa e Thap Maeo, 37,50\% para a cultivar Preciosa e 15,38\% para a cultivar PV 03-76. Este problema tem sido fator limitante para o processo de introduçáo e estabelecimento em bananeira. Dos explantes estabelecidos submetidos a corte longitudinal, houve contaminação fúngica em $20 \%$ dos explantes da cultivar Preciosa, provavelmente, devido à manipulação, pois os explantes estavam establecidos e este tipo de contaminaçáo ocorre na fase inicial do estabelecimento da cultura, diferentemente da contaminação por bactérias que se estendeu até a fase de multiplicação de brotos (Figura 3).

Segundo Lima e Moraes (2006) as taxas de contaminaçáo mais elevadas para a cultura da bananeira são de origem bacteriana. A fase mais suscetível desse tipo de contaminação é no estabelecimento da bananeira in vitro, com tendência de redução à medida que vão sendo realizados os subcultivos. Em um ambiente mais competitivo, os níveis de contaminaçôes atingidos podem inviabilizar a produção comercial de mudas de bananeira, sendo este o principal fator que onera o rendimento desta cultura (Braga et al. 2001).

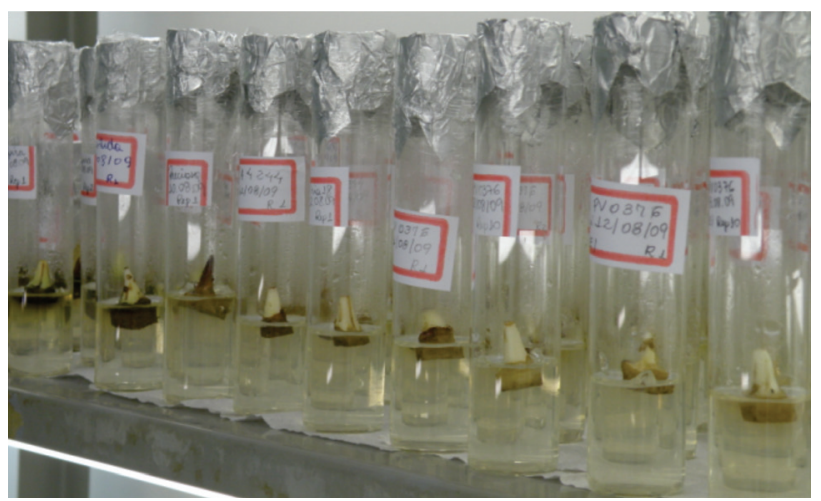

Figura 2 - Ápices Caulinares em meio MS suplementado com. $30 \mathrm{~g} \mathrm{~L}^{-1} \mathrm{de}$ sacarose, vitamina MS, 2,5 mg.L-1 de BAP, PVP a $4 \mathrm{~g} \mathrm{~L}^{-1}, 100 \mathrm{mg} \mathrm{L}^{-1} \mathrm{de}$ Sulfato de Estreptomicina solidificado e Phytagel a $2 \mathrm{~g} \mathrm{~L}^{-1}$ durante a etapa de estabelecimento.

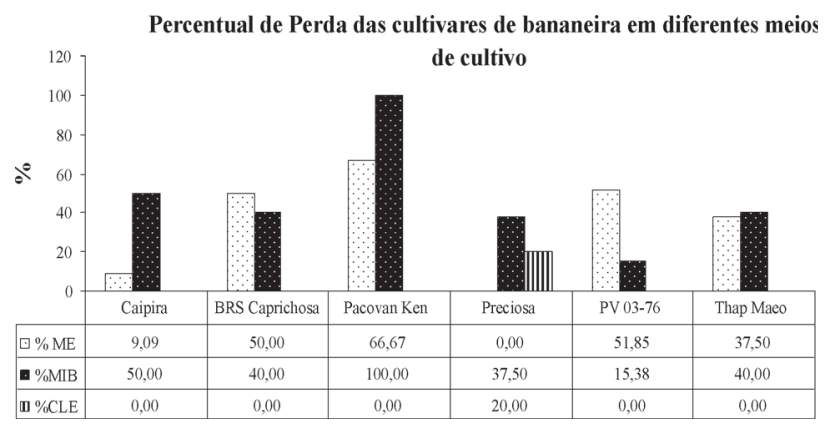

Figura 3 - Percentual de perda por contaminação e/ou oxidação das cultivares de bananeira após duas semanas de cultivo em diferentes fases do processo de estabelecimento da cultura. ME (meio de estabelecimento), MIB (em meio de indução de brotos) e CLE (meio usado após corte longitudinal do explante).

Segundo Lopes (1988), as contaminações bacterianas são mais drásticas que as fúngicas e trazem duas conseqüências básicas: a primeira é a perda de tempo e de recursos financeiros ou genéticos pela eliminação de frascos contaminados, e a segunda é o risco de contaminação de outras plantas.

Com exceção da cultivar Pacovan Ken que não apresentou multiplicação de brotos devido a perda de $100 \%$ dos seus explantes na etapa do estabelecimento da cultura, os explantes das cinco cultivares de bananeira estabelecidos apresentaram respostas variáveis quanto ao número de brotos/rizoma e brotos/explante em três subcultivos contínuos. Foi assinalada heterogeneidade de variância no caso de brotos/rizoma, mas em número de brotos/explante foi assinalada homogeneidade de variância. Após a transformação logarítimica, os dados apresentaram homocedasticidade (Tabela 1).

No primeiro subcultivo a taxa de multiplicação variou em média de 2,00 a 4,75 brotos/rizoma e média geral de 3,7 brotos/explante, dispersão das médias de 0,57 e diferença significativa entre as cultivares. 
Tabela 1- Valores dos testes de homocedasticidade de Hartley e Cochran para as medidas tomadas em cada um dos subcultivos e seus valores transformados

\begin{tabular}{|c|c|c|c|c|c|}
\hline \multirow{2}{*}{ Variável } & \multirow{2}{*}{ Transformação } & \multirow{2}{*}{ Sub-cultivo } & $F_{(\max )}$ & $C$ & \\
\hline & & & Hartley & Cochran & \\
\hline \multirow{3}{*}{ Brotos/rizoma } & & Sub-cultivo I & 19.67 & 0.70 & $p<0.05$ \\
\hline & & Sub-cultivo II & 140.00 & 0.77 & $p<0.01$ \\
\hline & & Sub-cultivo III & 271.38 & 0.90 & $p<0.01$ \\
\hline \multirow{2}{*}{ Brotos/explante } & & Sub-cultivo II & 15.36 & 0.48 & $p<0.20$ \\
\hline & & Sub-cultivo III & 4.12 & 0.40 & $p<0.80$ \\
\hline \multirow{3}{*}{ Brotos/rizoma } & logarítimica & Sub-cultivo I & 0.01 & 0.62 & $p<0.90$ \\
\hline & logarítimica & Sub-cultivo II & 26.30 & 0.56 & $p<0.20$ \\
\hline & logarítimica & Sub-cultivo III & 16.80 & 0.62 & $p<0.20$ \\
\hline
\end{tabular}

A cultivar Caipira que possui grupo genômico AAA, apresentou maior média de brotos $(4,75)$, diferindo estatisticamente ao nível de significância $5 \%$ de probabilidade da cultivar PV 03-76 (AAAB), que apresentou média de 2,00 brotos. Esta última náo diferiu das demais cultivares: BRS Caprichosa, Thap Maeo e Preciosa (Tabela 2 e Figura 4).

Tabela 2 - Brotos/rizoma produzidos durante o primeiro subcultivo para as diferentes cultivares de bananeira mantidas em meio MS suplementado com BAP $4,5 \mathrm{mg} \mathrm{L}^{-1}$.

\begin{tabular}{lc}
\hline Cultivar (Grupo genômico) & Média $^{1}$ \\
\hline Caipira (AAA) & $4,75 \mathrm{a}$ \\
\hline BRS Caprichosa (AAAB) & $4,00 \mathrm{ab}$ \\
\hline Thap Maeo (AAB) & $4,00 \mathrm{ab}$ \\
Preciosa (AAAB) & $3,75 \mathrm{ab}$ \\
\hline PV 03-76 (AAAB) & $2,00 \mathrm{~b}$ \\
Média Geral & 3,70 \\
\hline DMS(Tukey) & 2,49 \\
\hline CV (\%) & 30,82 \\
\hline
\end{tabular}

1 Letras iguais na mesma coluna não diferem estatisticamente entre si pelo teste de Tuckey a $5 \%$ de probabilidade. $\mathrm{CV}=$ Coeficiente de variação

Considera-se que as médias de brotos/rizoma de 2,00 a 4,75 são aceitáveis, uma vez que Vuylsteke e De Langhe (1985), Banerjee e De Langhe (1985), Wong (1986), Oliveira et al. (2001) obtiveram taxa de multiplicação de bananeira que variaram entre duas e dez plântulas por subcultivo a cada quatro ou cinco semanas. No entanto, segundo Jarret et al. (1985), podem ser obtidas até 31 plântulas por subcultivo.

No segundo subcultivo, a média da quantidade de brotos acumulados por rizoma por cultivar foi semelhante, estatisticamente, em virtude do aumento da taxa de indução de brotos naquelas cultivares com menores taxas do que o primeiro cultivo, porém no terceiro subcultivo houve diferença significativa entre as cultivares quanto ao número de brotos acumulados por rizoma (Tabelas 3 e Figura 4).

Ressalte-se que a cultivar Caipira (AAA) apresentou maiores médias de brotos/rizoma, tanto no segundo $(11,50)$ quanto no terceiro $(41,50)$ subcultivos, sem significância no segundo subcultivo entre as cultivares, mas com taxa de multiplicação no terceiro subcultivo significativamente superior à cultivar Thap Maeo (AAB) de 11,00 brotos/rizoma.

Quanto à média de brotos/explante, a cultivar Caipira (AAA) apresentou maior média $(3,69)$ após o terceiro subcultivo, porém sem diferir significativamente das demais cultivares. No segundo subcultivo, a cultivar Thap Maeo (AAB) apresentou maior média $(2,81)$, diferindo estatisticamente apenas da cultivar BRS Caprichosa (AAAB). Este fato permitiu que não houvesse diferença significativa quanto a brotos/rizoma no segundo subcultivo, mas com significância no terceiro subcutivo pela cultivar caipira ter apresentado maior número de brotos/explante no primeiro subcultivo e mantido uma maior taxa no terceiro subcultivo (Tabela 3 e Figura 5).

As cultivares apresentaram taxas médias de multiplicação de brotos diferentes em cada subcultivo. A cultivar Caipira (AAA) se destacou tanto em número de brotos/rizoma quanto em brotos/explante, indicando a alta capacidade de resposta desse genótipo à multiplicação de plantas no processo de micropropagaçáo. Em trabalho realizado por Lima e Moraes (2006), o genótipo Caipira apresentou rendimento (taxa de multiplicação estimada acumulada) de pelo menos duas vezes superior aos demais genótipos no quinto subcultivo, sendo que a taxa de multiplicaçáo também variou entre os genótipos estudados.

Segundo Jarret (1986), existem diferenças significativas na capacidade de multiplicaçáo in vitro de cada cultivar de bananeira, embora todos os genótipos tenham respondido favoravelmente à técnica de micropropagação por ápices caulinares. Neste trabalho, não foram observadas grandes diferenças quanto ao número de plântulas obtidas por explante inicial das cultivares de grupos genômicos triplóides $\mathrm{AAA}$ e $\mathrm{AAB}$, embora Sandoval et al. (1991) salientem que existem diferenças inclusive entre clones de uma mesma cultivar.

Foi observado que após o terceiro subcultivo, a média geral das cultivares foi de 2,64 brotos/explante. Resultados 
Tabela 3 - Brotos/rizomas e brotos/explante, após o segundo e terceiro subcultivos de cultivares de bananeira em meio MS suplementado com BAP 4,5 mg L-1.

\begin{tabular}{lcccc}
\hline & \multicolumn{2}{c}{ Médias de Brotos/rizoma } & \multicolumn{2}{c}{ Médias de Brotos/explante } \\
\hline Cultivares (Grupo genômico) & $2^{\circ}$ Subc. & $3^{\circ}$ Subc. & $2^{\circ}$ Subc. & $3^{\circ}$ Subc. \\
\hline Caipira (AAA) & $11,50 \mathrm{a}$ & $41,50 \mathrm{a}$ & $2,40 \mathrm{ab}$ & $3,69 \mathrm{a}$ \\
\hline BRS Caprichosa (AAAB) & $8,25 \mathrm{a}$ & $21,25 \mathrm{ab}$ & $1,90 \mathrm{~b}$ & $2,24 \mathrm{a}$ \\
\hline Thap Maeo (AAB) & $5,25 \mathrm{a}$ & $11,00 \mathrm{~b}$ & $2,81 \mathrm{a}$ & $2,81 \mathrm{a}$ \\
\hline Preciosa (AAAB) & $8,00 \mathrm{a}$ & $19,75 \mathrm{ab}$ & $2,12 \mathrm{ab}$ & $2,31 \mathrm{a}$ \\
PV 03-76 (AAAB) & $7,50 \mathrm{a}$ & $18,25 \mathrm{ab}$ & $2,62 \mathrm{ab}$ & $2,17 \mathrm{a}$ \\
\hline Média Geral & 8,10 & 22,35 & 2,37 & 2,64 \\
\hline DMS (Tukey) & 6,56 & 27,77 & 0,78 & 1,73 \\
CV (\%) & 37,11 & 56,89 & 15,07 & 30,13 \\
\hline
\end{tabular}

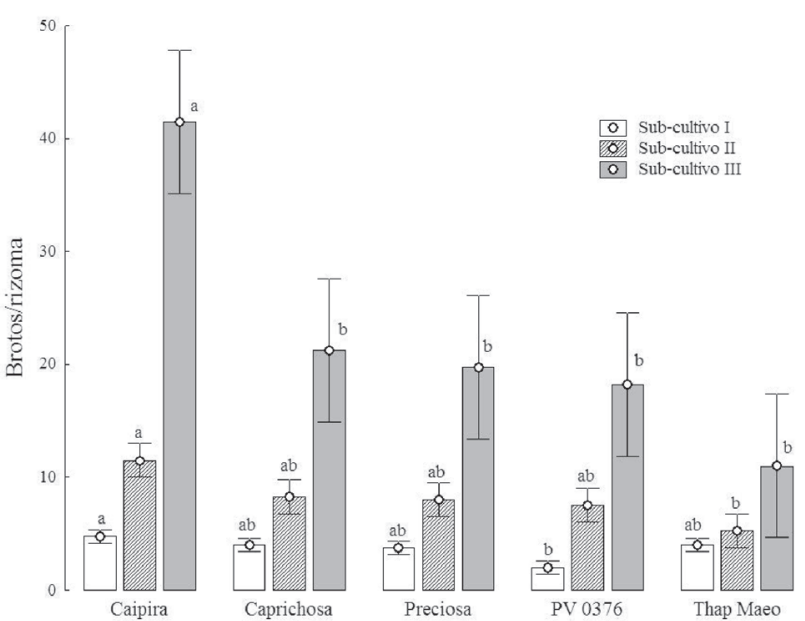

Figura 4 - Médias de brotos/rizoma por cultivar em três subcultivos em meio MS suplementado com BAP 4,5 mg L-1.

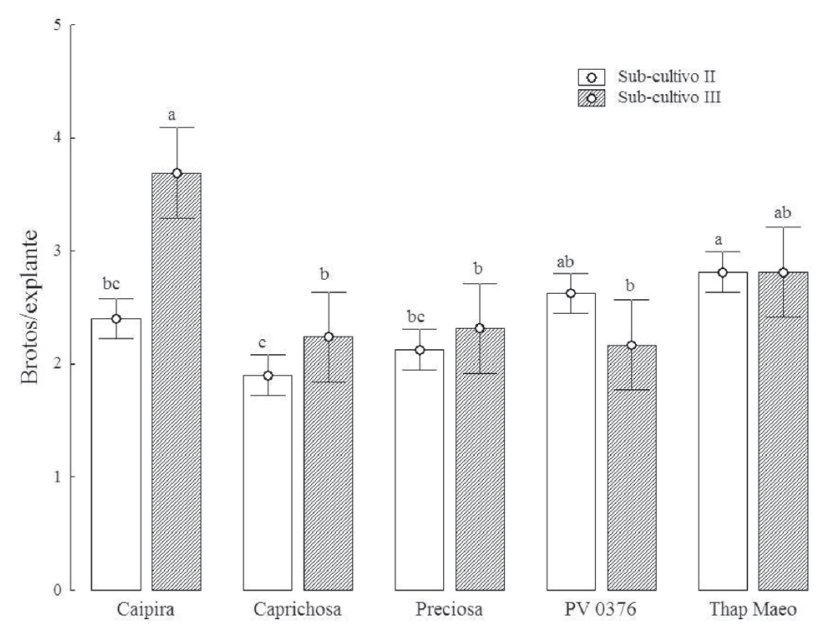

Figura 5 - Médias de brotos/explante em cada cultivar em três subcultivos contínuos em meio MS suplementado com BAP 4,5mg. $\mathrm{L}^{-1}$. semelhantes foram encontrados por Oliveira et al. (2001) em que a taxa média de multiplicaçáo foi de 2,53 brotos/explante por subcultivo, no meio de cultura em que foi adicionado 2,5 $\mathrm{mg} \mathrm{L}^{-1}$ de BAP.

\section{CONCLUSÕES}

A micropropagação de mudas de bananeira das cultivares Caipira (AAA), BRS Caprichosa (AAAB), Preciosa (AAAB), PV 03-76 (AAAB) e Thap Maeo (AAB), resistentes a doenças, segundo o método avaliado, aumenta a quantidade de material vegetal com alta qualidade genética e fitossanitária.

Dentre as cultivares micropropagadas a cultivar caipira (AAA) tem maior capacidade de multiplicação de brotos, destacando-se com média de 41,50 brotos por rizoma, após três subcultivos.

Os usos do antioxidante PVP na concentração 0,4\% e do antibiótico sulfato de estreptomicina na concentraçáo de 100 $\mathrm{mg} \mathrm{L}^{-1}$ são eficientes na redução da oxidação e nos aspectos de contaminação, respectivamente, independente da cultivar de banana utilizada.

\section{AGRADECIMENTOS}

Ao CNPq pela bolsa de mestrado concedida, à Embrapa Amazônia Oriental pelo apoio logístico. Trabalho como parte da dissertação de mestrado.

\section{BIBLIOGRAFIA CITADA}

Angarita, A.; Perea, M. 1991. Micropropagación de plátanos y bananos, p. 495-512. In: Roca, W.M.; Mroginski, L.A. (Eds.). Cultivo de tejidos en la agricultura.

Augusto, C.S.S.; Biasi, L.A. 2002. Micropropagation of blackbarry cv. Brazos. Scientia Agrária, 3: 113-132 (in Portuguese, with abstract in English).

Álvares, M.C.; Caldas, L.S. 2002. Growth, yield and somaclonal variation of micropropagated bananas. Pesquisa agropecuária brasileira, 37: 415-420 (in Portuguese, with abstract in English). 
Banerjee, N.; De Langhe, E. 1985. A tissue culture technique for rapid clonal propagation and storage under minimal growth conditions of Musa (banana and plantain). Plant Cell Reports, 4: 351-354.

Borges, A.L.; Oliveira, A.M.G.; Ritzinger, C.H.S.P.; Almeida, C.O.; Coelho, E.F.; Santos-Serejo, J.A.; Souza, L.S.; Lima, M.B; Fancelli, M.; Folegatti, M.I.S.; Filho, P.E. M.; Silva, S.; Medina, V.M.; Cordeiro, Z.J.M. 2006. A cultura da bananal Embrapa Mandioca e Fruticultura Tropical, Embrapa Informação Tecnológica, (Coleçâo Plantar, 56).

Braga, M.F.; Sá, M.E.L.; Mustafá, P.C. 2001. Evaluation of a commercial protocol for in vitro multiplication of banana (Musa sp) cv. Caipira (AAA). Revista Brasileira de Fruticultura, 23: 215219 (in Portuguese, with abstract in English).

Cordeiro, I.M.C.C.; Lameira, O.A.; Lopes, S.C.; Rios, M.S. 2002. Germinação in vitro de paricá. Biotecnologia Ciência e Desenvolvimento, 27

Cronauer, S.S.; Krikorian, A.D. 1984. Multiplication potencial of Musa from excised stem tips. Annals of Botany, 53: 321-328.

Ferreira, D.F. 2009. Uso de Recursos Computacionais Utilizando R. LAVRAS, Minas Gerais - Brasil.

Figueiredo, S.F.L; Albarello N; Viana V.R.C. 2001. Micropropagation of Rollinia mucosa (jacq.) Baill. In Vitro Cell Developmental Biology Plant, 37: 471-475.

Grattapaglia, D.; Machado, M.A. 1998. Micropropagação, p. 183260. In: Torres, A. C.; Caldas, L. S.; Buso, J. A. Cultura de tecidos e transformação genética de plantas, v. 1.

Grattapaglia, D.; Machado, M.A. 1990. Micropropagaçáo, 99-169. In: torres, A.C.; Caldas, L.S. (Eds.). Técnicas e aplicaçōes da cultura de tecidos de plantas. Brasília: Embrapa-CNPH.

Hwang, S.C.; Chen, C.L.; Lin, J.C.; Lin, H.L. 1984.Cultivation of banana using plantlets from meristem culture. HortScience, 19: 231-233.

Jarret, R.L. 1986. In vitro propagation and genetic conservation of bananas and plantains. IBPGR advisory committee on in vitro storage, 15-33.

Jarret, R.L.; Rodriguez, W.; Fernandez, R. 1985. Evaluation, tissue culture propagation, and dissemination of Saba and Pelipita plantains in Costa Rica. Scientia Horticulturae, 25: 137-147.

Lima, J.D.; Moraes, W.S. 2006. Concentration of bap and evaluation of in vitro multiplication protocol for banana genotypes. Pesquisa Agropecuária Tropical, 36: 13-19 (in Portuguese, with abstract in English).

Lopes, C.A. 1988. Contaminaçóes bacterianas em cultura de tecidos. ABCTP Noticias, 13: 35-40.

Melo, B; Pinto, J.E.B.P; Luz, J.M.Q.; Peixoto, J.R.; Juliatti, F.C. 2001. Use of different antioxidants for the control of oxidation, germination and development of the seedlings in the in vitro embryo culture of the guarirobeira [syagrus oleracea (mart.) becc.]. Ciência e Agrotecnologia, 25: 1301-1306 (in Portuguese, with abstract in English).

Murashige, T.; Skoog, F. 1962. A revised medium for rapid growth and bioassays with tobacco tissue cultures. Physiologia Plantarum, 15: 473-497.

Nascimento, W.M.O.; Müller, C.H. ; Carvalho, J.E.U.; Martins, L.L.; Lemos, O.F. 2009. Avaliação de cultivares de bananeira em resistência à sigatoka-negra em Belém, PA. Belém: Embrapa Amazônia Oriental. Comunicado Técnico, n. 218

Oliveira, R.P.; Silveira, D.G.; Silva, S.O. 2001. BAP concentration and tetraploid banana micropropagation efficiency (AAAB group) Scientia Agricola, 58:73-78 (in Portuguese, with abstract in English).

Pasqual M; Hoffmann, A; Ramos J.D. 1997. Cultura de tecidos vegetais: tecnologia e aplicaçôes - introdução: fundamentos básicos. Lavras: UFLA/FAEPE. 159 pp.

Poltronieri, L.S.; Figueiredo, D.V.; Brioso, P.S.T.; Verzignassi, J.R.; Cardoso, S.S. 2009. Constataçáo do Banana streak Uganda B virus em bananeiras no Estado do Pará, Summa Phytopathol, 35: 74 .

Produção Agricola Municipal: culturas temporárias e permanentes/ IBGE. - v.1 (1974) - Rio de Janeiro: IBGE, 1977 v. Anual. Continuação de Levantamento da produção agrícola municipal, Rio de Janeiro, 35: 1-93, 2008.

Sá, M.E.L.; Braga, M.F. 2002. Evaluation of a protocol to obtain micropropagated plantlets of banana cv. prata-aná (subgroup AAB). Revista Brasileira de Fruticultura, 24: 236-239 (in Portuguese, with abstract in English).

Sandoval, J.A.; Brenes, G.; Pérez Sánchez, L. 1991. Micropropagación de plátano y banano (Musa AAB, AAA) en el Catie. (Informe Técnico, 186).

Silva, E.A.; Boliani, A.C.; Corrêa, L.S. 2006. Evaluation of banana (Musa sp) cultivars in Selvíria-MS region, Revista Brasileira de Fruticultura, 28: 101-103.

Souza, A.S.; Cordeiro, Z.J.M.; Trindade, A.V. 2000. Produção de mudas, p.39-46. In: Cordeiro, Z.J.M. Banana: produção. Brasília, DF: Embrapa Comunicação para Transferência de Tecnologia.

Vuylsteke, D.; Langhe, E. 1985. Feasibility of in vitro propagation of bananas and plantains. Tropical Agriculture, 62: 323-328.

Wong, W.C. 1986. In vitro propagation of banana (Musa spp.): initiation, proliferation and development of shoot-tip cultures on defined media. Plant Cell, Tissue and Organ Culture, 6: 159-166.

Recebido em 25/02/2010

Aceito em 15/12/2010 